\title{
Numerical Simulation and Measurement of Air Temperature and Relative Humidity in an Olive Cuttings Tunnel Greenhouse
}

\author{
Sanae Chakir ${ }^{1 *}$, Adil Bekraoui1 ${ }^{1}$, Hassan Majdoubi1,2, Allal Senhaji1, Mhamed Mouqallid1 \\ ${ }^{1}$ Department of Energy, ENSAM, University Moulay Ismail, Meknes, Morocco \\ ${ }^{2}$ Laboratory of Scientific Research and Pedagogical Development, Fes-Meknes, Morocco \\ Email: *chakir.sanae@gmail.com
}

How to cite this paper: Chakir, S., Bekraoui, A., Majdoubi, H., Senhaji, A. and Mouqallid, M. (2022) Numerical Simulation and Measurement of Air Temperature and Relative Humidity in an Olive Cuttings Tunnel Greenhouse. Open Journal of Modelling and Simulation, 10, 32-47.

https://doi.org/10.4236/ojmsi.2022.101002

Received: October 5, 2021

Accepted: December 6, 2021

Published: December 9, 2021

Copyright $\odot 2022$ by author(s) and Scientific Research Publishing Inc. This work is licensed under the Creative Commons Attribution International License (CC BY 4.0).

http://creativecommons.org/licenses/by/4.0/

\begin{abstract}
Understanding the environment of olive tree cuttings is a key factor in improving these plants' rooting rate and survival. This study aims to develop a three-dimensional (3-D) Computational Fluid Dynamics (CFD) model for numerically assessing air temperature and relative humidity in an olive cuttings greenhouse under Mediterranean climatic conditions. The results are deduced from a steady-state simulation performed with recorded boundary conditions at 10:00 am, 12:00 pm, 02:00 pm, 04:00 pm, and 06:00 pm at different observation points. The calculations were validated using experimental data. The simulation errors of the air temperature were $-0.8^{\circ} \mathrm{C}$ to $4.55^{\circ} \mathrm{C}$, and errors of the leaf temperature were $0.07^{\circ} \mathrm{C}$ to $2.42^{\circ} \mathrm{C}$, for the air relative humidity was $-33.84 \%$ to $-1.64 \%$, and $-10.1 \%$ to $-13.54 \%$ for the relative humidity of the leaf air. Contour maps were obtained from the 3-D CFD simulations to evaluate the distribution of humidity and air temperature inside the greenhouse and the vicinity of the plant canopy. This study suggests that the developed 3-D CFD model can be a helpful tool to understand and optimize greenhouse operation for better crop quality.
\end{abstract}

\section{Keywords}

Numerical Simulation, Computational Fluid Dynamics, Greenhouse, Microclimate, Olive Cuttings

\section{Introduction}

With the increasing consumption of olive products and, therefore, the current specialization in disseminating the dietary, nutritional and organoleptic qualities of vegetable oil, it becomes necessary to extend the productivity of this fruit 
worldwide [1]. Propagation is an indispensable part of the olive production chain, and is the first stage in the establishment of olive growing or the renovation of existing orchards. Olives are usually propagated by cuttings in a greenhouse [2] [3].

The cuttings greenhouse must respect two main constraints: to protect the young plants from external climatic conditions and create a permanent climate favorable to the cuttings creating roots [4]. Different types of agricultural greenhouses are designed, such as tunnels greenhouses, the most structure used in Mediterranean regions [5]. These installations must maintain a high level of humidity (90\%) and an ideal temperature between $20^{\circ} \mathrm{C}$ and $27^{\circ} \mathrm{C} \mathrm{[6]} \mathrm{[7].} \mathrm{So,} \mathrm{the} \mathrm{poor}$ control of environmental factors in the cuttings environment attributes to a low rooting percentage of olive cuttings [6] [8]. Understanding and improving greenhouse climate control and management to increase the rooting rate is the wish of farmers.

With advances in computing, scientists and engineers have widely adopted Computational Fluid Dynamics (CFD) tools to predict the prevailing climate within agricultural buildings [9] [10]. The popularity of CFD tools stems from their ability to compute the spatial distribution of the climate parameters within the whole greenhouse. These codes allow accurate simulations to be administered for a good range of geometric conditions and limits, which will help engineers and farmers improve greenhouse design and control [11]. Many CFD studies on greenhouse have been conducted. Still, the originality of our research is reflected in the fact that it is among the first few studies which concern this type of greenhouse dedicated to the rooting of cuttings, which is the essential step in the olive production chain.

The primary objectives of this study were to develop a 3-D CFD model for numerically assessing climatic variables in an olive cuttings greenhouse under Mediterranean wintertime climate conditions, and provide a helpful tool in improving greenhouse climate control, with a concern to increase the yield and quality of this crop. The model is first validated by the measured data, and then it is used to explore the details of temperature and humidity distributions.

\section{Materials and Methods}

\subsection{D CFD Simulation}

\subsubsection{Fundamental Equations}

The mass, energy, momentum, and concentration equations are often represented for a steady-state, three-dimensional flow with the subsequent conservation equation:

$$
\frac{\partial\left(u^{*} \phi\right)}{\partial x}+\frac{\partial\left(v^{*} \phi\right)}{\partial y}+\frac{\partial\left(w^{*} \phi\right)}{\partial z}=\Gamma \cdot \nabla^{2} \phi+S_{\phi}
$$

where $\phi$ represents the concentration of the transported quantity in a dimensional form, namely the 3-D momentum (Navier-Stokes) and the scalar mass and energy conservation equations; $u^{*}, v^{*}, w^{*}$ are the reduced forms of the compo- 
nents of velocity vector; $x, y$ and $z$ are the Cartesian space coordinates; $\Gamma$ is the diffusion coefficient; $S_{\phi}$ is the source term; and $\nabla^{2}$ is the Laplace operator [12].

Turbulence was modeled according to the standard $\mathrm{k}-\varepsilon$ model [13]. This method is based on solving two equations. One is for $\mathrm{k}$, which represents turbulent kinetic energy, and the other is for $\mathcal{E}$, which considers the energy dissipation rate in units of volume and time. This is the most widely used and validated turbulence model in many research studies in greenhouse CFD greenhouse literature [14] [15] [16].

The contribution of radiation was added in "Equation (1)" as a source component. The discrete ordinates model (DOM) of radiation solves the Radiative Transfer Equation (RTE) for a finite number of discrete solid angles, each related with a vector direction fixed in the global Cartesian system. The DO allows the solution of the radiation on semi-transparent materials (e.g., plastic).

The DOM writes the RTE in the direction $s$ as a field equation. The RTE for the spectral intensity $I_{\lambda}(\boldsymbol{r}, \boldsymbol{s}) \boldsymbol{s}$ can be written as [17]:

$$
\begin{aligned}
& \nabla \cdot\left(I_{\lambda}(\boldsymbol{r}, \boldsymbol{s}) \boldsymbol{s}\right)+\left(a_{\lambda}+\sigma_{\lambda}\right) I_{\lambda}(\boldsymbol{r}, \boldsymbol{s}) \\
& =a_{\lambda} n^{2 I_{b \lambda}}+\frac{\sigma_{s}}{4 \pi} \int_{\bigcap}^{4 \pi} I_{\lambda}\left(\boldsymbol{r}, \boldsymbol{s}^{\prime}\right) \Phi\left(\boldsymbol{s}, \boldsymbol{s}^{\prime}\right) \mathrm{d} \Omega^{\prime}
\end{aligned}
$$

where $\boldsymbol{r}$ is the position vector, $\boldsymbol{s}$ is the direction vector, $\boldsymbol{s}^{\prime}$ is the scattering direction vector, $\sigma$ is the Stefan-Boltzmann constant, $I_{\lambda}$ is the radiation intensity of the wavelength, $a_{\lambda}$ is the spectral absorption coefficient, $I_{b \lambda}$ is the black-body intensity given by the Planck function, $a_{s}$ is the scattering coefficient, $n$ is the refractive index, $\phi$ is the phase function and $\Omega^{\prime}$ is the solid angle (radian). In present study the number of bands is 3 , with UV radiation wave band from $0-0.4 \mu \mathrm{m}$, visible radiation waveband from $0.4-0.7 \mu \mathrm{m}$ and IR radiation waveband from $0.7-100 \mu \mathrm{m}$.

To take account of the gravity effect, the Boussinesq model was activated, which means that the buoyancy force due to air density differences is added as a source term of the momentum equation [18].

Without being able to take into account and describe the geometry of a real canopy, the plants were assimilated to an equivalent homogenous porous medium that induces a drag force calculated from the Darcye Forchheimer law [19]. The corresponding sink of momentum by unit of volume of the canopy was expressed by the commonly used formula established by Thom (1971) [20], which involves a drag coefficient:

$$
S_{\phi}=-\rho_{a} L A D C_{D} V^{2}
$$

where, $\rho_{a}$ is the air density $\left(\mathrm{kg} \cdot \mathrm{m}^{-3}\right), L A D$ is the leaf area density $\left(\mathrm{m}^{2} \cdot \mathrm{m}^{-3}\right)$ defined as the leaf area index divided by the canopy height, $C_{D}$ is the drag coefficient and $V$, the air velocity.

In addition to their influence on flow dynamics, plants also significantly alter the general energy balance. 
The crop was divided into elementary volumes in which the heat and water vapor mass transfers were modelled by sink or source terms. Each elementary volume receives a radiative flux that is converted into sensible and latent heat. The energy balance may be written as:

$$
G_{a}+Q_{s}+Q_{l}=0
$$

where $G_{a}\left(\mathrm{~W} \cdot \mathrm{m}^{-3}\right)$ is the density of net radiation (i.e. radiative flux divided by cell height) absorbed in each canopy cell, $Q_{I}\left(\mathrm{~W} \cdot \mathrm{m}^{-3}\right)$ is the latent heat flux density associated with the transpiration process, and $Q_{s}\left(\mathrm{~W} \cdot \mathrm{m}^{-3}\right)$ is the sensible heat flux density transferred between the leaves and the ambient air.

The net radiation was obtained by dividing the difference between the downward and upward long wave radiation by the height of the canopy. The canopy-to-air sensible heat flux density $\left(Q_{s}\right)$ is a function of the difference in temperature between the leaves and the ambient air, as well as of the leaf density. It is governed by the following equation [19]:

$$
Q_{s}=2 L A D \frac{\rho_{a} C_{p}}{r_{a}}\left(T_{1}-T_{a}\right)
$$

where $C_{p}$ is the specific heat of air under constant pressure $\left(\mathrm{J} \cdot \mathrm{kg}^{-1} \cdot \mathrm{K}^{-1}\right), r_{a}$ is the leaf aerodynamic resistance $\left(\mathrm{s} \cdot \mathrm{m}^{-1}\right)$, and $T_{l}$ and $T_{a}$ are the temperatures of leaves and air, respectively, inside each cell. The factor 2 that appears in "Equation (5)" indicates that sensible heat transfers occur on both sides of the leaves. This formula also assumes that the temperatures on both sides of the leaf are the same. The relationship between the leaf aerodynamic resistance and the heat transfer coefficient $(h)$ for individual leaves may be written as [21]:

$$
r_{a}=\frac{\rho_{a} C_{p}}{h}
$$

The heat transfer coefficient $(h)$ was calculated from the Nusselt number, Prandtl number, Glaschoff number, and Reynolds number according to the equation of Montero et al. (2001) [22], which distinguishes between free convection, forced convection, and mixed convection.

The latent heat flux or the transpiration rate $Q_{l}$ was deduced from a similar relation with respect to air humidity difference between $W_{I}\left(\mathrm{~kg} \cdot \mathrm{kg}^{-1}\right)$, the saturated water content of the air at canopy temperature and $w_{a}\left(\mathrm{~kg} \cdot \mathrm{kg}^{-1}\right)$, the specific humidity of the air [23]:

$$
Q_{l}=L A D \frac{L_{w} \rho_{a}}{r_{s}+r_{a}}\left(W_{l}-W_{a}\right)
$$

with, $L_{w}\left(\mathrm{~kJ} \cdot \mathrm{kg}^{-1}\right)$ the latent heat of water vaporization and $r_{s}\left(\mathrm{~s} \cdot \mathrm{m}^{-1}\right)$ the leaf stomatal resistance.

\subsubsection{Numerical Procedure}

The numerical solution was obtained by means of a finite volume discretization code, together with the simple (implicit method for pressure linked equations) pressure-velocity coupling algorithm. To achieve an accurate result, second-order 
upwind discretization schemes were used for momentum and turbulence equations. The convergence criterion for all variables was $1 \times 10^{-6}$. A specific user-defined functions (UDFs) have been developed to take into account the interaction of crops with the environment. Table 1 summarizes the basic components of CFD simulation.

\section{Experimental Procedures}

\subsection{Site and Greenhouse Description}

The experiment was performed on January 31th, 2020. The experimental greenhouse was a closed delata9 type tunnel with a steel frame. The dimensions of this greenhouse were $20.67 \mathrm{~m}$ in length, $9.52 \mathrm{~m}$ in width, and $2.95 \mathrm{~m}$ in maximum height. Olive cuttings occupied the greenhouse with a density of 2500 plants $/ \mathrm{m}^{2}$, in rows oriented NE - SW. The canopy (h) was $0.15 \mathrm{~m}$ high on average. The greenhouse was located in central Morocco (longitude: $31^{\circ} \mathrm{N}$, latitude: $5^{\circ} \mathrm{N}$ ). There are sprinkler systems and a shading layer outside the tunnel, and the misting system inside.

\subsection{Measurement System and Condition Limits}

Global radiation, temperature, and relative humidity were measured by a weather station located outside the greenhouse. The temperature and relative humidity of the indoor air and the leaf air were measured with model SHT35 sensors: 5 positions at the height of $1.25 \mathrm{~m}$ (Figure 1) for air parameters and one place in the middle for leaf air parameters. The substrate and plastic cover temperatures

Table 1. The basic components of CFD simulation.

\begin{tabular}{|c|c|}
\hline Classification & Setting of Method \\
\hline Solver & $\begin{array}{c}\text { Segregated solver } \\
\text { 3-D simulation } \\
\text { Implicit formulation } \\
\text { Absolute velocity formation } \\
\text { steady state analysis (first-order implicit) }\end{array}$ \\
\hline Energy Equation & Activated \\
\hline Viscous Model & $\begin{array}{c}\text { Standard k- } \mathcal{E} \text { model } \\
\text { Standard wall functions }\end{array}$ \\
\hline Radiation Model & $\begin{array}{c}\text { DO (discrete ordinates) } \\
\text { Theta divisions: } 2 \\
\text { Phi divisions: } 2 \\
\text { Theta pixels: } 1 \\
\text { Phi pixels: } 1 \\
\text { Non-grey model: selected; with } 3 \text { bands } \\
\text { Iteration ratio (flow/radiation): } 10\end{array}$ \\
\hline Species & Multiple species \\
\hline UDF & Developed \\
\hline
\end{tabular}




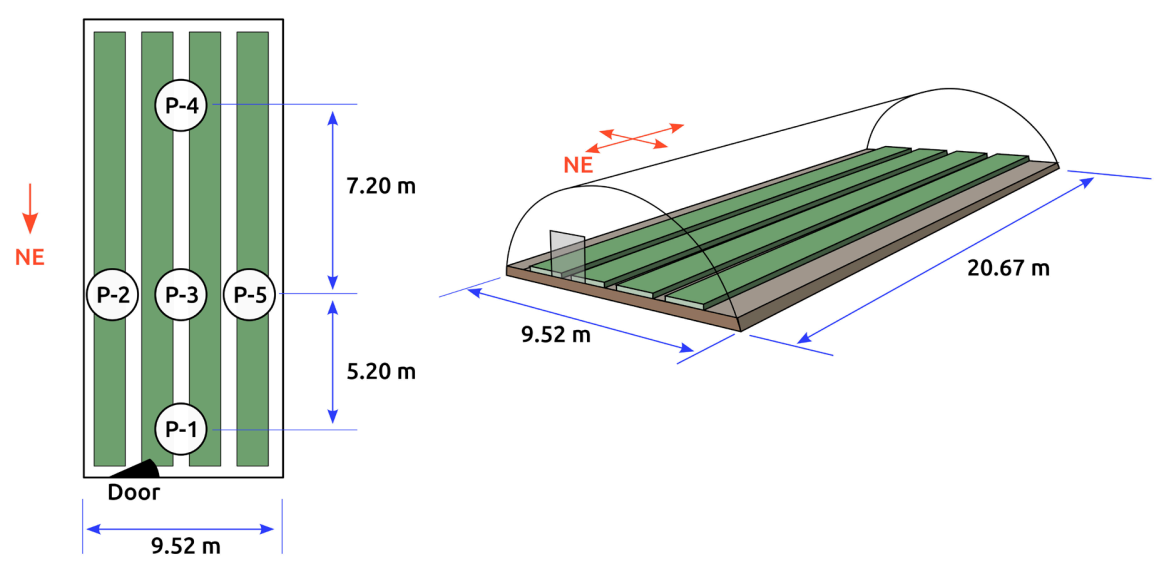

Figure 1. Schematic view of sensors locations inside the studied greenhouse.

were measured in the middle position with PT 100 sensors (Table 2).

The boundary characteristics are presented in Table 3. The results were deduced from a steady-state simulation performed with the boundary conditions recorded at 10:00 am, 12:00 pm, 02:00 pm, 04:00 pm and 06:00 pm.

For the simulation, it is necessary to define the different materials that composing the greenhouse and their properties (Table 4).

\section{Results and Discussion}

\subsection{Temperature}

The simulated results were compared to the experimentally measured data, as shown in Figure 2 for the indoor air temperature and Figure 3 for the leaf-air temperature. The absolute errors of the simulated values from the experimental data were $-0.8^{\circ} \mathrm{C}$ to $4.55^{\circ} \mathrm{C}$ for the indoor air temperature and $0.07^{\circ} \mathrm{C}$ to $2.24^{\circ} \mathrm{C}$ for the leaf air temperature, as summarized in Table 5. By analyzing these values, we observe that the results of 10:00 am, 4:00 pm and 6:00 pm indicate a close agreement between the values of simulation and the experimental measurements.

On the other hand, the values of the temperature at noon and 2:00 pm. is overestimated; this difference can be explained by the use of a system of cooling by misting and, in parallel, another system of cooling outside during this period.

From this study, we can deduce that using these two cooling systems only lowers the air temperature of the greenhouse by a maximum of $4.55^{\circ} \mathrm{C}$. However, the system studied still does not manage to maintain the temperature favourable to the optimal growth of young olive trees saplings. Indeed, the relatively high temperatures inside the greenhouse (above $27^{\circ} \mathrm{C}$ ) would have the effect of increasing transpiration, which corresponds to the rate of evaporation of water into the atmosphere from a given area of leaves and plant stems in given weather [23]. The lower the internal resistance of the leaf to the diffusion of water, the more transpiration increases rapidly with the air temperature, which causes activation of the auxiliary buds and the fall of the leaves, and consequently 
Table 2. Characteristics of the sensors used in this experiment.

\begin{tabular}{cccc}
\hline Parameters & Sensors & Unity & Accuracy \\
\hline Air temperature & SHT35 & ${ }^{\circ} \mathrm{C}$ & $\pm 0.2^{\circ} \mathrm{C}$ \\
Relative humidity & SHT35 & $\%$ & $\pm 1.5 \%$ \\
Substrate and cover temperatures & PT100 & ${ }^{\circ} \mathrm{C}$ & 4.55 \\
Global solar radiation & HYXC-HYGTRA/B & $\mathrm{W} / \mathrm{m}^{2}$ & $<5 \%$ \\
\hline
\end{tabular}

Table 3. The Experimental measurement used as boundary conditions for the numerical simulation (31th January, 2020).

\begin{tabular}{cccccc}
\hline & $\begin{array}{c}\text { Global solar } \\
\text { radiation } \\
\left(\mathrm{w} / \mathrm{m}^{2}\right)\end{array}$ & $\begin{array}{c}\text { Outside air } \\
\text { temperature } \\
\left({ }^{\circ} \mathrm{C}\right)\end{array}$ & $\begin{array}{c}\text { Outside } \\
\text { relative air } \\
\text { humidity } \\
(\%)\end{array}$ & $\begin{array}{c}\text { Plastic roof } \\
\text { cover } \\
\text { temperature } \\
\left({ }^{\circ} \mathrm{C}\right)\end{array}$ & $\begin{array}{c}\text { Substrate } \\
\text { temperature } \\
\left({ }^{\circ} \mathrm{C}\right)\end{array}$ \\
\hline $10: 00 \mathrm{pm}$ & 250 & 12.88 & 56.17 & 19.21 & 14.69 \\
$12: 00 \mathrm{pm}$ & 611 & 19.77 & 29.12 & 39.39 & 19.95 \\
$14: 00 \mathrm{pm}$ & 673 & 21.99 & 22.43 & 41.05 & 24.75 \\
$16: 00 \mathrm{pm}$ & 505 & 22.48 & 24.29 & 31.56 & 25.60 \\
$18: 00 \mathrm{pm}$ & 115 & 19.33 & 31.77 & 21.79 & 24.18 \\
\hline
\end{tabular}

Table 4. Physical properties of common building materials.

\begin{tabular}{cccccc}
\hline & $\begin{array}{c}\text { Density } \\
\left(\mathrm{Kg} \cdot \mathrm{m}^{-3}\right)\end{array}$ & $\begin{array}{c}\text { Specific heat } \\
\left(\mathrm{J} \cdot \mathrm{kg}^{-1} \cdot{ }^{\circ} \mathrm{C}^{-1}\right)\end{array}$ & $\begin{array}{c}\text { Absorption } \\
\text { coefficient } \\
\text { (for solar } \\
\text { radiation) }\end{array}$ & $\begin{array}{c}\text { Scattering } \\
\text { coefficient } \\
\text { (for solar } \\
\text { radiation) }\end{array}$ & $\begin{array}{c}\text { Refractive } \\
\text { index }\end{array}$ \\
\hline Substrate & 1900 & 2200 & 2 & 0.5 & 1 \\
Cover & 2000 & 840 & 0.78 & 0.1 & 1.4 \\
Concrete & 2100 & 880 & 1.4 & 0.6 & 1 \\
Plant & 700 & 2310 & 0.173 & $\begin{array}{c}\text { User defined } \\
\text { gray band }\end{array}$ & 1 \\
\hline
\end{tabular}

Table 5. Absolute errors of the simulated temperature values to the measured values at each position for different day hours.

\begin{tabular}{cccccc}
\hline & $10: 00 \mathrm{am}$ & $12: 00 \mathrm{pm}$ & $02: 00 \mathrm{pm}$ & $04: 00 \mathrm{pm}$ & $06: 00 \mathrm{pm}$ \\
\hline P-1 & -0.05 & 0.92 & 0.20 & -0.56 & -0.35 \\
P-2 & -0.15 & 2.80 & 2.99 & -0.01 & -0.62 \\
P-3 & 0.16 & 4.42 & 4.55 & 0.49 & -0.14 \\
P-4 & -0.02 & 4.14 & 3.92 & 0.16 & -0.79 \\
P-5 & 0.06 & 2.78 & 1.73 & -0.80 & -0.75 \\
P-leaf-air & 0.10 & 1.60 & 2.24 & 0.20 & 0.07 \\
\hline
\end{tabular}




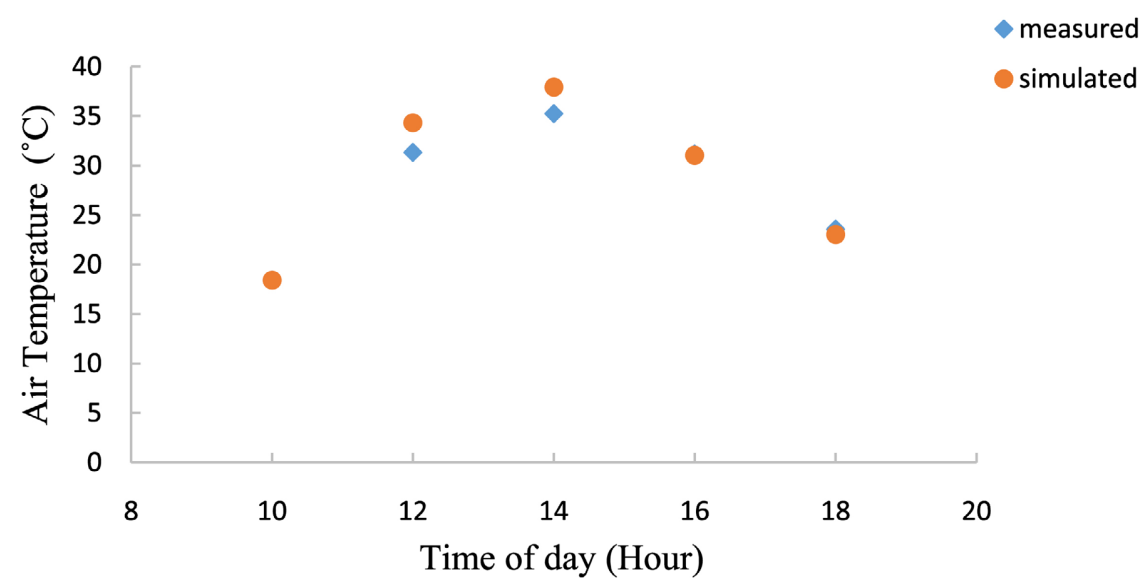

Figure 2. Comparison of measured and simulated average air temperature value of the five positions, for different hours of the day.

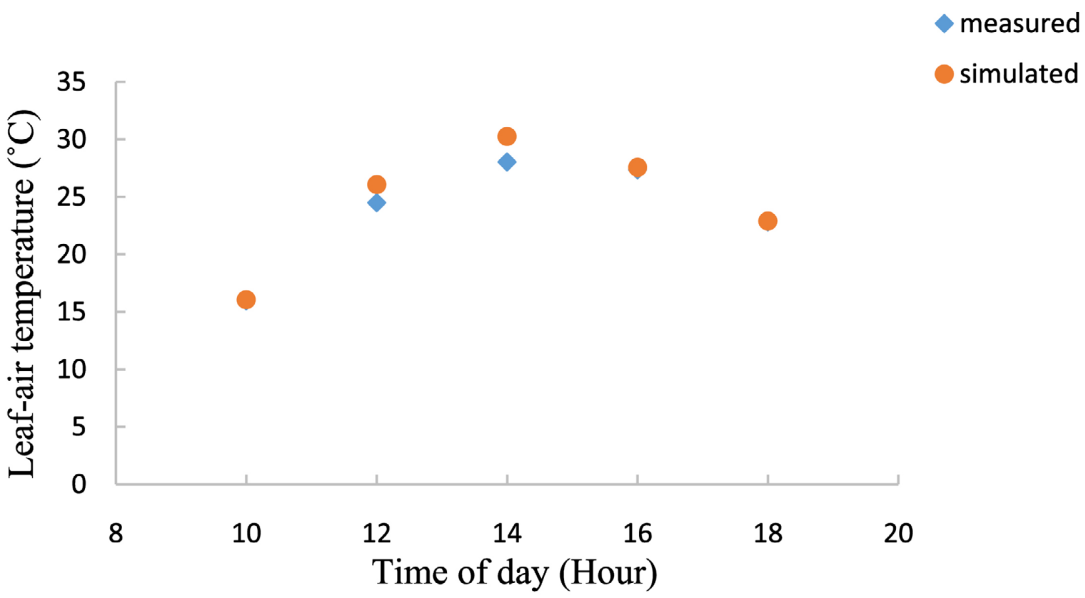

Figure 3. Comparison of measured and simulated leaf air temperature value for different hours of the day.

a decrease in the rate of rooting. For this purpose, a release of excess heat to the outside using natural ventilation must be programmed between noon and 2:00 pm.

The temperature distribution in the greenhouse (Figure 4) confirms that the leaf air temperature is slightly lower than the air temperature, especially at noon and 2:00 pm. Light indirectly affects perspiration by altering stomatal resistance. Stomata opening are stimulated by light [24] [25]. In addition, and during these two times, a gradient temperature is observed; this gradient is due to the increase in temperature and the buoyancy force [18]. Also, this figure showed us a remarkable horizontal homogeneity of the air temperature inside the greenhouse. On the other hand, the greenhouse air, approximately $80 \%$ at 10:00 am and more than $80 \%$ at 4:00 and 6:00 pm, is in the same temperature range. However, this percentage does not exceed $40 \%$ at noon and 2:00 pm (Table 6); this heterogeneity is explained by the distribution of solar radiation inside the greenhouse [19]. From these results, we can conclude that this system can ensure temperature homogeneity, representing an essential advantage for this crop. 


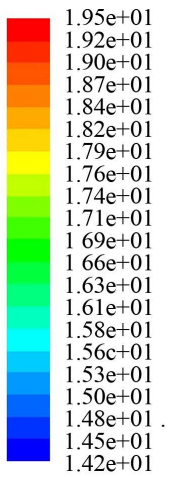

$1.42 \mathrm{e}+01$
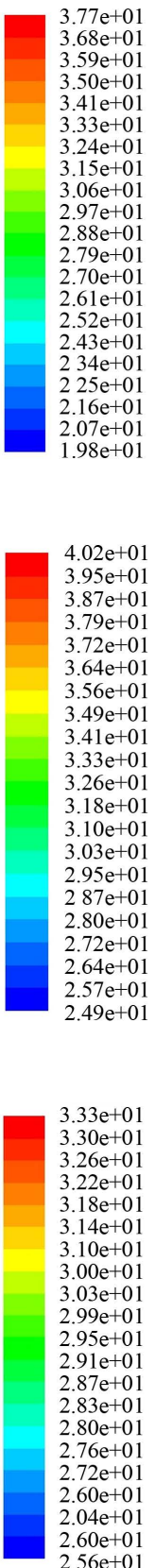

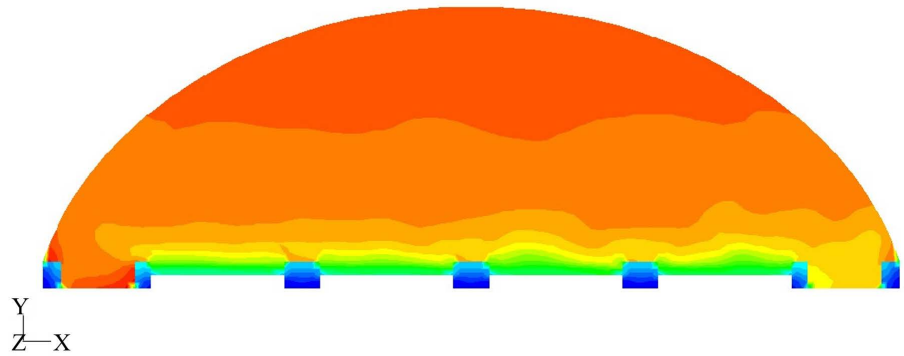

(a)

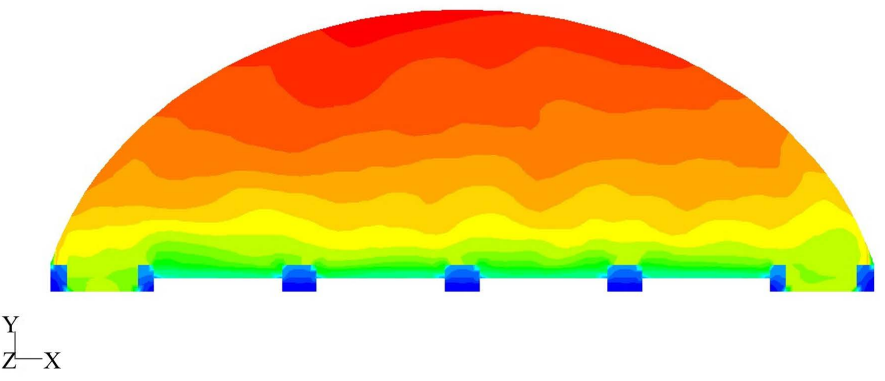

(b)

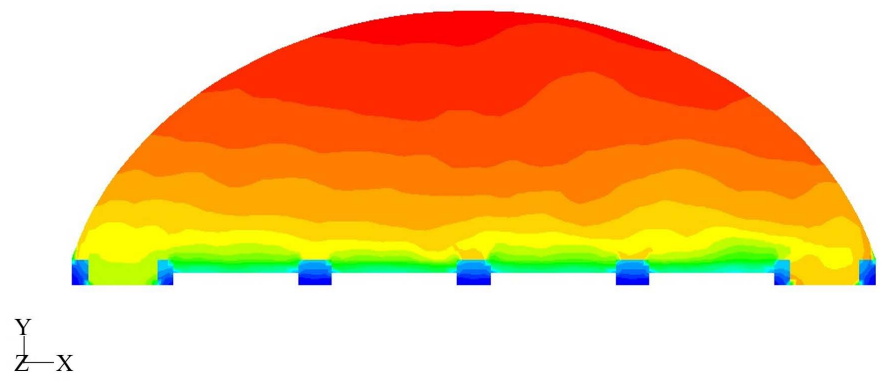

(c)

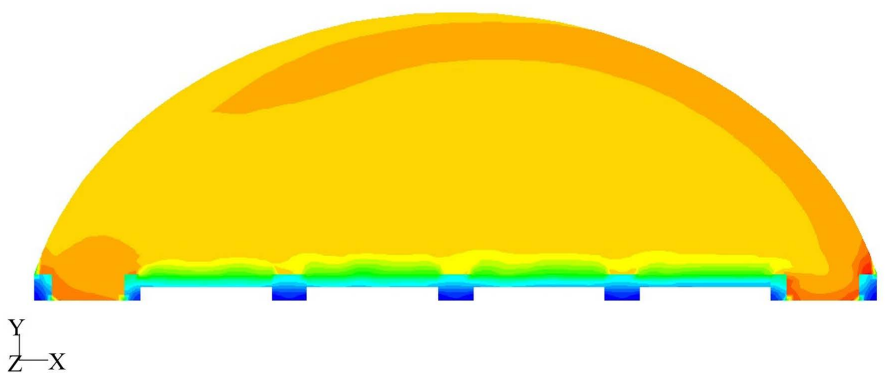

(d) 


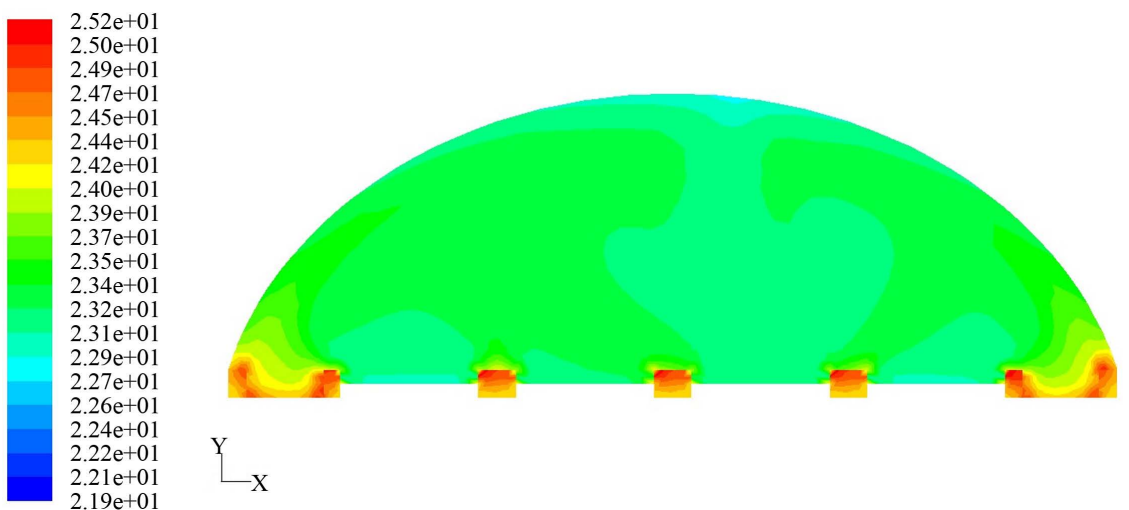

(e)

Figure 4. Sectional-view contour maps of air temperature distribution inside the greenhouse (plan XY at $\mathrm{z}=11 \mathrm{~m}$ ): (a) at 10:00 am; (b) at 12:00 pm; (c) at 02:00 pm; (d): at 04:00 $\mathrm{pm}$; (e) at 06:00 pm.

Table 6. The percentage of the greenhouse air in the same temperature range for different day hours.

\begin{tabular}{rcc}
\hline & Temperature range & Percentage of air greenhouse \\
\hline $10: 00 \mathrm{am}$ & $18.08^{\circ} \mathrm{C}-19.18^{\circ} \mathrm{C}$ & $86 \%$ \\
$12: 00 \mathrm{pm}$ & $30.88^{\circ} \mathrm{C}-32.72^{\circ} \mathrm{C}$ & $32 \%$ \\
$02: 00 \mathrm{pm}$ & $35.90^{\circ} \mathrm{C}-37.48^{\circ} \mathrm{C}$ & $35 \%$ \\
$04: 00 \mathrm{pm}$ & $30.56^{\circ} \mathrm{C}-31.38^{\circ} \mathrm{C}$ & $79 \%$ \\
$06: 00 \mathrm{pm}$ & $22.45^{\circ} \mathrm{C}-23.57^{\circ} \mathrm{C}$ & $93 \%$ \\
\hline
\end{tabular}

\subsection{Relative Humidity}

The values of simulated relative humidity in the greenhouse and the canopy air for different hours of the day are presented in Figure 5 and Figure 6 respectively, The absolute error of simulated values compared to the experimental data were $-33.34 \%$ minimum to $-1.61 \%$ maximum for indoor relative humidity, and from $-13.54 \%$ minimum to $-10.1 \%$ maximum for the relative humidity of the leaf air as summarized in Table 7, overall the relative humidity values are underestimated especially between noon and 2:00 pm, which can be explained by the non-consideration of the irrigation system water and also the outdoor cooling system in our simulation model.

The humidity distribution in the greenhouse showed that the relative humidity of the plant canopy is always higher than $80 \%$ (Figure 7); this increase is related primarily to the plant's transpiration and the confinement of the air inside the greenhouse. The relative humidity is very sensitive to the variation of the ventilation rate, and that this one, in our case, is almost zero inside the greenhouse. In contrast, the relative humidity knows a fall until $50 \%$ between noon and 2:00 pm in the air of the greenhouse; this fall is related to the increase of the temperature. As already presented, the relative humidity is among the key 


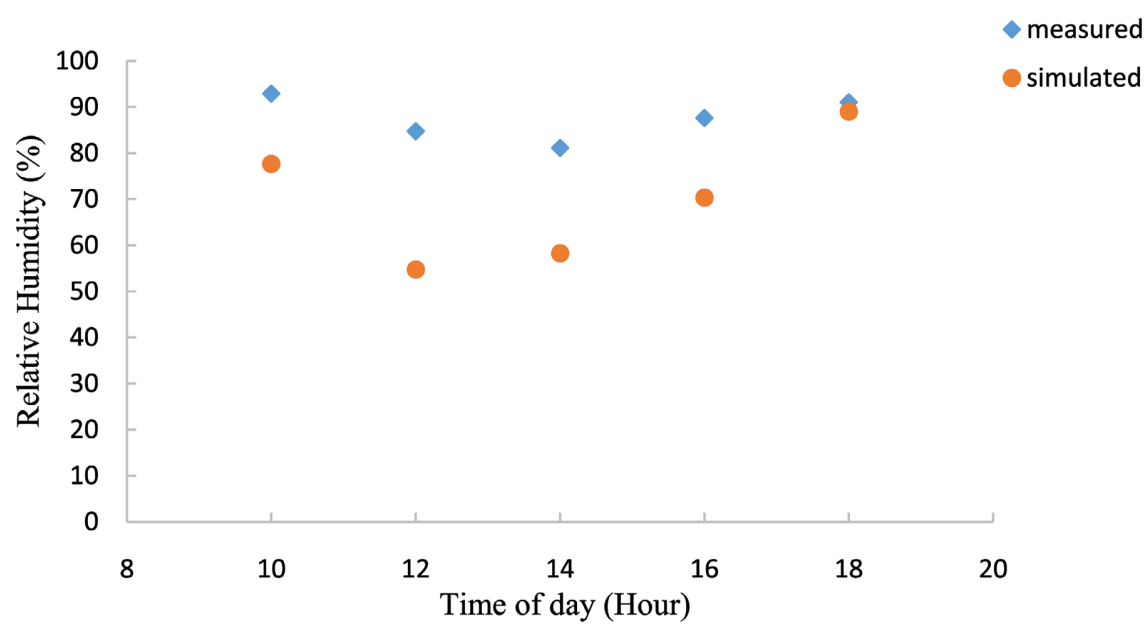

Figure 5. Comparison of measured and simulated average relative humidity values of the five positions for different hours of the day.

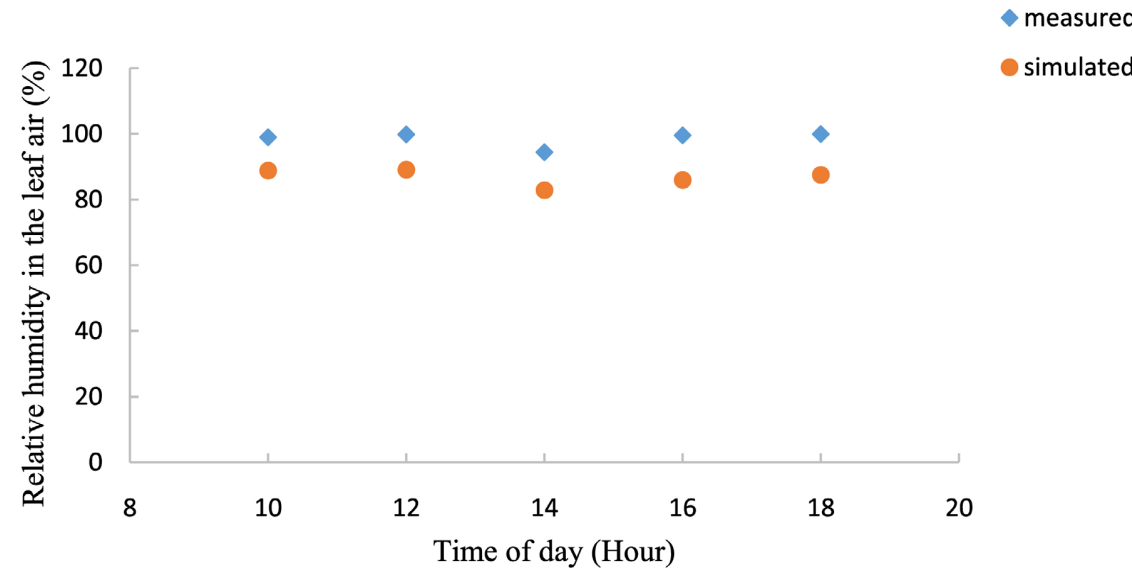

Figure 6. Comparison of measured and simulated relative humidity values in the leaf air for different hours of the day.

Table 7. Absolute errors of the simulated relative humidity values to the measured values at each position for different day hours.

\begin{tabular}{cccccc}
\hline & $10: 00 \mathrm{am}$ & $12: 00 \mathrm{pm}$ & $02: 00 \mathrm{pm}$ & $04: 00 \mathrm{pm}$ & $06: 00 \mathrm{pm}$ \\
\hline P-1 & -9.44 & -28.06 & -19.75 & -14.09 & -1.61 \\
P-2 & -14.88 & -28.92 & -24.93 & -20.92 & -2.76 \\
P-3 & -18.4 & -33.34 & -25.41 & -20.58 & -2.01 \\
P-4 & -16.17 & -26.83 & -20.08 & -13.54 & -1.8 \\
P-5 & -17.13 & -32.88 & -24.29 & -17.08 & -1.83 \\
P-leaf-air & -10.1 & -10.8 & -11.56 & -13.54 & -12.37 \\
\hline
\end{tabular}

environmental factors for the success of cuttings, the absence of roots does not allow the cutting to maintain its maximum turgidity potential, so the maintenance of high relative humidity, without saturating the substrate excessively, 


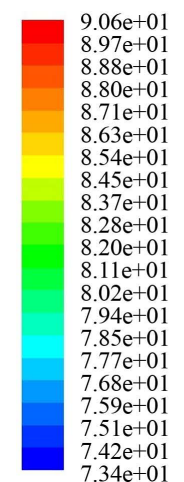

$7.34 \mathrm{e}+01$
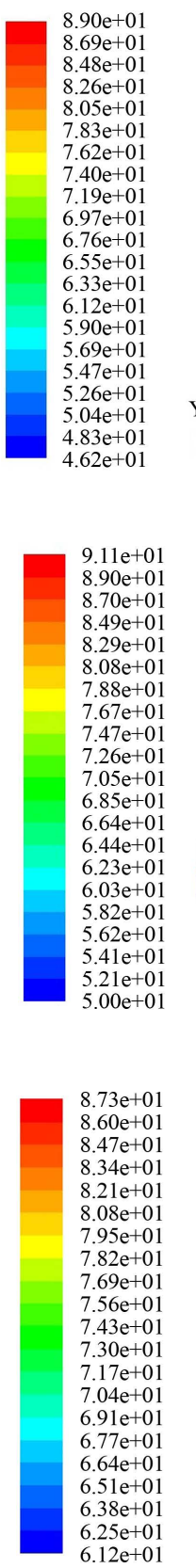

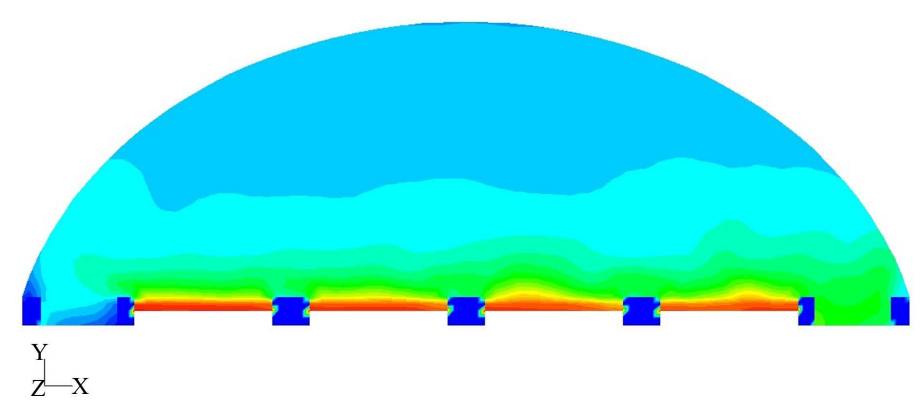

(a)

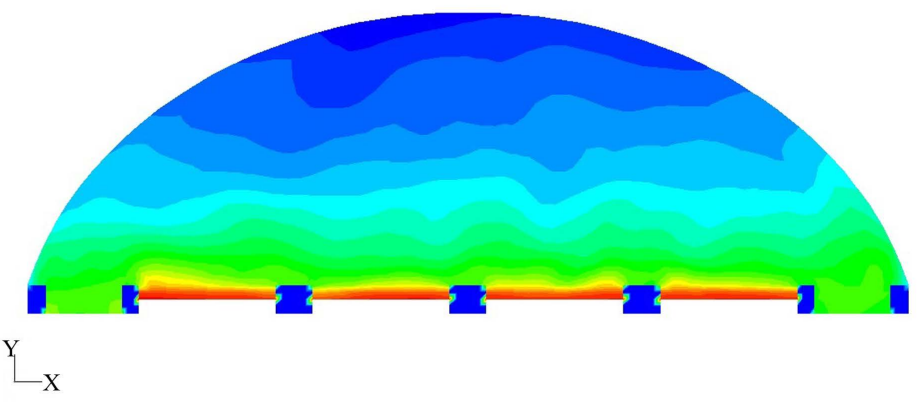

(b)

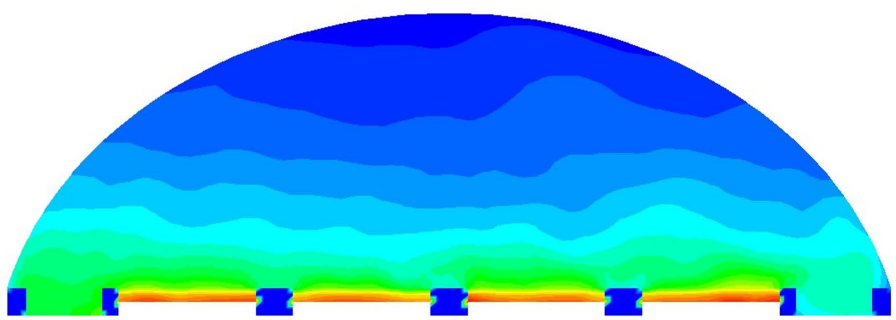

$\mathrm{L}_{\mathrm{X}}$

(c)

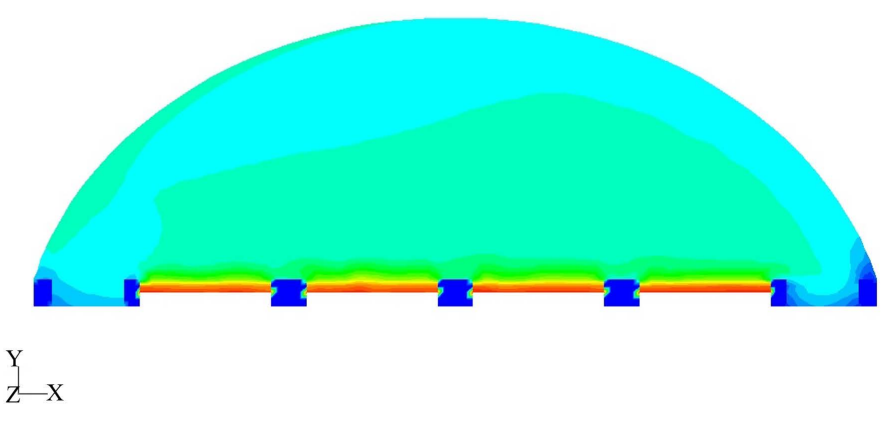

(d) 

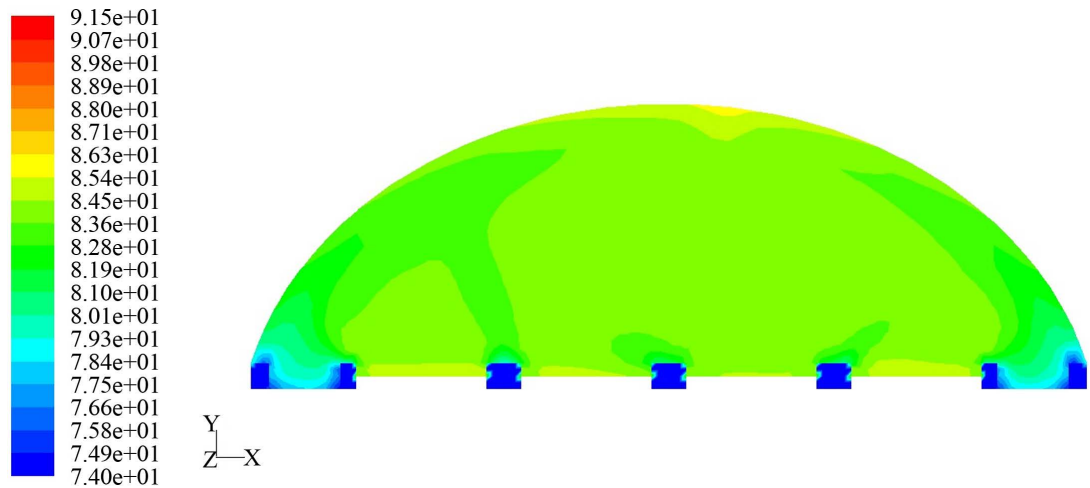

(e)

Figure 7. Sectional-view contour maps of relative humidity distribution inside the greenhouse: (a) at 10:00 am; (b) at 12:00 pm; (c) 02:00 pm; (d): at 04:00 pm; (e) at 06: 00 pm.

Table 8. The percentage of the greenhouse air in the same relative humidity range for different day hours.

\begin{tabular}{ccc}
\hline & Temperature range & Percentage of air greenhouse \\
\hline $10: 00 \mathrm{am}$ & $73 \%-82 \%$ & $95 \%$ \\
$12: 00 \mathrm{pm}$ & $54 \%-63 \%$ & $47 \%$ \\
$02: 00 \mathrm{pm}$ & $56 \%-65 \%$ & $63 \%$ \\
$04: 00 \mathrm{pm}$ & $63 \%-72 \%$ & $91 \%$ \\
$06: 00 \mathrm{pm}$ & $82 \%-95 \%$ & $95 \%$ \\
\hline
\end{tabular}

reduces the hydric stress conferred to the cuttings and favours rooting [5] [26]. Therefore, this simulation result has shown that practicing a misting system makes it possible to increase the relative humidity of the air of the greenhouse and the leaf (up to 33\% maximum), which represents an advantage for the process. Finally, and as presented for the temperature, a uniform distribution of the air inside the greenhouse is essential to ensuring the success of the cuttings; Figure 5 indicates a remarkable horizontal homogenization of the relative humidity of the air inside the greenhouse. Table 8, which represents the percentage of the greenhouse air in the same range of the relative humidity, confirms overall the homogeneity of the relative humidity inside the greenhouse.

\section{Conclusions}

A 3-D CFD model was developed to simulate air temperature and relative humidity distribution in a tunnel greenhouse for rooting cuttings. The developed model provided good overall agreement with the experimental measurements. This model showed the limitation of the two cooling systems' effect on the excess of internal heat during the day. It lowers the air temperature of the greenhouse by a maximum of $4.55^{\circ} \mathrm{C}$, hence the need to equip this greenhouse with natural ventilation openings. On the other hand, this simulation result showed that the prac- 
tice of a misting system allows increasing the relative humidity of the air in the greenhouse and the leaf (up to $33 \%$ maximum).

Furthermore, this study confirmed that this type of greenhouse allows homogenization of climatic parameters for the success of the rooting process. The results obtained previously could be a means in future research to improve the efficiency of the greenhouse by a thorough analysis of all the difficulties of root cutting according to the Spatio-Temporal distribution of the microclimate. Furthermore, a similar study should be conducted on other greenhouse designs to determine which one is adequate for root development.

\section{Acknowledgements}

We are grateful and indebted to many members of the nursery teams who helped with the tremendous amount of practical work that enabled us to carry out this study.

\section{Conflicts of Interest}

The authors declare no conflicts of interest regarding the publication of this paper.

\section{References}

[1] Schuch, M.W., Tomaz, Z.F.P., Casarin, J.V., Moreira, R.M. and Silva, J.B.D. (2019) Advances in Vegetative Propagation of Olive Tree. Revista Brasileira de Fruticultura, 41, e-003. https://doi.org/10.1590/0100-29452019003

[2] Porfírio, S., Gomes Da Silva, M.D., Cabrita, M.J., Azadi, P. and Peixe, A. (2016) Reviewing Current Knowledge on Olive (Olea europaea L.) Adventitious Root Formation. Scientia Horticulturae, 198, 207-226.

https://doi.org/10.1016/j.scienta.2015.11.034

[3] Denaxa, N.K., Vemmos, S.N. and Roussos, P.A. (2012b) The Role of Endogenous Carbohydrates and Seasonal Variation in Rooting Ability of Cuttings of an Easy and a Hard to Root Olive Cultivars (Olea europaea L.). Scientia Horticulturae, 143, 19-28. https://doi.org/10.1016/j.scienta.2012.05.026

[4] Laurent, U. (2010) La production sous serre. Tome 1 LA gestion du climat. 2nd Edition, TECHNIQUE \& DOC.

[5] Tüzel, Y. and Katsoulas, N. (2021) Protected Cultivation in Mediterranean Region. Acta Horticulturae, 1315, 323-334. https://doi.org/10.17660/ActaHortic.2021.1315.49

[6] Sbay, H. and Lamhamedi, M.S. (2015) Guide pratique de multiplication végétative des espèces forestière: Technique de valorisation et de conservation des espèces à usage multiples face aux changements climatiques en Afrique du nord. Royaume du Maroc, haut-commissariat aux eaux et forêts et à la lutte contre la désertification, centre de recherche forestière, 1-34.

[7] Goldammer, T. (2021) Greenhouse Management: A Guide to Operations and Technology. Apex Publishers.

[8] Sebastiani, L. and Tognetti, R. (2004) Growing Season and Hydrogen Peroxide Effects on Root Induction and Development in Olea europaea L. (cvs "Frantoio" and “Gentile di Larino") Cuttings. Scientia Horticulturae, 100, 75-82. 
https://doi.org/10.1016/j.scienta.2003.08.008

[9] Norton, T., Sun, D.W., Grant, J., Fallon, R. and Dodd, V. (2007) Applications of Computational Fluid Dynamics (CFD) in the Modelling and Design of Ventilation Systems in the Agricultural Industry: A Review. Bioresource Technology, 98, 2386-2414. https://doi.org/10.1016/j.biortech.2006.11.025

[10] Bournet, P.E. and Boulard, T. (2010) Effect of Ventilator Configuration on the Distributed Climate of Greenhouses: Review of Experimental and CFD Studies. Computers and Electronics in Agriculture, 74, 195-217. https://doi.org/10.1016/j.compag.2010.08.007

[11] Nebbali, R., Roy, J. and Boulard, T. (2012) Dynamic Simulation of the Distributed Radiative and Convective Climate within a Cropped Greenhouse. Renewable Ener$g y, 43,111-129$. https://doi.org/10.1016/j.renene.2011.12.003

[12] Kim, K., Yoon, J.Y., Kwon, H.J., Han, J.H., Eek Son, J., Nam, S.W., Giacomelli, G.A. and Lee, I.B. (2008) 3-D CFD Analysis of Relative Humidity Distribution in Greenhouse with a Fog Cooling System and Refrigerative Dehumidifiers. Biosystems Engineering, 100, 245-255. https://doi.org/10.1016/j.biosystemseng.2008.03.006

[13] Launder, B.E. and Spalding, D.B. (1972) Lectures in Mathematical Models of Turbulence. Academic Press, London.

[14] Boulard, T. and Wang, S. (2000) Greenhouse Crop Transpiration Simulation from External Climate Conditions. Agricultural and Forest Meteorology, 100, 25-34. https://doi.org/10.1016/S0168-1923(99)00082-9

[15] Nebbali, R., Roy, J.C., Boulard, T. and Makhlouf, S. (2006) Comparison of the Accuracy of Different CFD Turbulence Models for the Prediction of the Climatic Parameters in a Tunnel Greenhouse. Acta Horticulturae, 719, 287-294.

https://doi.org/10.17660/ActaHortic.2006.719.32

[16] Ali, H.B., Bournet, P.E., Cannavo, P. and Chantoiseau, E. (2018) Development of a CFD Crop Submodel for Simulating Microclimate and Transpiration of Ornamental Plants Grown in a Greenhouse under Water Restriction. Computers and Electronics in Agriculture, 149, 26-40. https://doi.org/10.1016/j.compag.2017.06.021

[17] He, X., Wang, J., Guo, S., Zhang, J., Wei, B., Sun, J. and Shu, S. (2018) Ventilation Optimization of Solar Greenhouse with Removable Back Walls Based on CFD. Computers and Electronics in Agriculture, 149, 16-25.

https://doi.org/10.1016/j.compag.2017.10.001

[18] Majdoubi, H., Boulard, T., Fatnassi, H. and Bouirden, L. (2009) Airflow and Microclimate Patterns in a One-Hectare Canary Type Greenhouse: An Experimental and CFD Assisted Study. Agricultural and Forest Meteorology, 149, 1050-1062. https://doi.org/10.1016/j.agrformet.2009.01.002

[19] Boulard, T. and Wang, S. (2002) Experimental and Numerical Studies on the Heterogeneity of Crop Transpiration in a Plastic Tunnel. Computers and Electronics in Agriculture, 34, 173-190. https://doi.org/10.1016/S0168-1699(01)00186-7

[20] Thom, A.S. (1971) Momentum Absorption by Vegetation. Quarterly Journal of the Royal Meteorological Society, 97, 414-428. https://doi.org/10.1002/qj.49709741404

[21] Bailey, B., Montero, J., Biel, C., Wilkinson, D., Anton, A. and Jolliet, O. (1993) Transpiration of Ficus benjamina: Comparison of Measurements with Predictions of the Penmane-Monteith Model and a Simplified Version. Agricultural and Forest Meteorology, 65, 229-243. https://doi.org/10.1016/0168-1923(93)90006-4

[22] Montero, J.I., Anton, A., Munoz, P. and Lorenzo, P. (2001) Transpiration from Geranium Grown under High Temperatures and Low Humidities in Greenhouses. Agricultural and Forest Meteorology, 107, 323-332. 
https://doi.org/10.1016/S0168-1923(01)00215-5

[23] Baille, M., Baille, A. and Laury, J.C. (1994) A Simplified Model for Predicting Evapotranspiration Rate of Nine Ornamental Species vs. Climate Factors and Leaf Area. Scientia Horticulturae, 59, 217-232. https://doi.org/10.1016/0304-4238(94)90015-9

[24] Gerosa, G. (2011) Evapotranspiration-From Measurements to Agricultural and Environmental Applications. IntechOpen, London. https://doi.org/10.5772/991

[25] Driesen, E., van den Ende, W., de Proft, M. and Saeys, W. (2020) Influence of Environmental Factors Light, $\mathrm{CO}_{2}$, Temperature, and Relative Humidity on Stomatal Opening and Development: A Review. Agronomy, 10, 1975. https://doi.org/10.3390/agronomy10121975

[26] Alem, P. (2010) Unrooted Stem Cutting Physiology; Water Use and Leaf Gas Exchange of Severed Stem Cuttings. All Theses, 918.

https://tigerprints.clemson.edu/all theses/918 